\title{
Barriers to Perinatal Care among Migrant Women Farmworkers in Northern Ohio
}

\author{
Stacey A. Pilling ${ }^{*}$, Larissa J. Estes \\ College of Health Sciences, Public Health Walden University, USA
}

Copyright (C) 2016 by authors, all rights reserved. Authors agree that this article remains permanently open access under the terms of the Creative Commons Attribution License 4.0 International License

\begin{abstract}
The purpose of this qualitative study was to examine the barriers that may inhibit migrant women farmworkers' management of perinatal care while working in Northern Ohio. Face-to-face interviews were conducted with 15 migrant women farmworkers who had experienced at least one gestational period while working in the Midwest agricultural stream. Participants were voluntarily recruited using purposeful sampling. All participants reported several occupational and access barriers that hindered them from receiving perinatal care while working in the fields. These findings may inform public health providers and migrant healthcare clinicians of the barriers migrant women farmworkers' experience while working in Northern Ohio; results can also be used to influence local and national migrant healthcare policies on developing comprehensive maternal healthcare.
\end{abstract}

Keywords Migrant Women Farmworkers, Perinatal Care, Qualitative Research, Rural Health, Minority Health

\section{Introduction}

Migrant and seasonal farmworkers are a vital component of the multi-billion dollar fruit and vegetable industry in the United States [1, 2]. This industry relies on the ability of a temporary workforce to plant, maintain, and harvest crops for distribution [3]. The National Center for Farmworker Health (NCFH) estimates there are 3-5 million migrant farmworkers who, along with their families, travel throughout the United States, providing labor and expertise to the agricultural industry $[1,3]$. Of the $3-5$ million migrant laborers, approximately $22 \%$ are women [4] and a large portion of the women are of childbearing age [5].

Like men, migrant women farmworkers are exposed to many physical, chemical, and biological hazards that pose potential human health risks. However, women of childbearing age are at an increased risk of having reproductive health difficulties and adverse pregnancy outcomes as a result of employment [4, 6, 7]. Women farmworkers perform the same labor as men, which is known to be extremely intensive with workdays often lasting from dawn to dusk in all conditions, including high temperatures, rain, and bright sun [6-9]. However, little is known about reproductive health and pregnancy outcomes for migrant women farmworkers in the US due to their transient lifestyle and clandestine nature [10].

Data from the Pregnancy Nutrition Surveillance System determined that out of 4,840 migrant women farmworkers examined in California $23.8 \%$ had unfavorable birth outcomes such as low birthweights, premature births, or small for gestational age [4]. Premature births and low birthweights are indicators of social inequality [11] and directly related to high morbidity and mortality rates [12, 13].

One method to reduce the likelihood of adverse pregnancy outcomes is perinatal care [14-18]. Perinatal care can be defined as the period between the decision to become pregnant or aware of pregnancy and 4-6 weeks after birth; thus, including both prenatal and postnatal care [18]. Prenatal care begins typically begins two to three months prior to conception and involves preventive health care measures including regular checkups to treat and prevent potential problems throughout the course of the pregnancy [18]. Postnatal care consists of care for both the mother and child for the first 6-8 weeks post-partum [18]. Thus the purpose of this study was to examine the barriers that may inhibit migrant women farmworkers' management of perinatal care while working in the fields in Northern Ohio.

\section{Methods}

This study, conducted in Northern Ohio, used in-depth open-ended interview questions to collect data. This approach allowed study participants to discuss potential barriers to managing perinatal care while working in the fields using their own words. 


\section{Participants and Recruitment}

This study enrolled adult migrant women farmworkers between the ages of 18-40 years. This age range was selected based on the premise that older, mature women may have diminished memories of some of the challenges of maintaining perinatal health while working in the agricultural fields. Additionally, participants must have experienced a minimum of one gestational period while working in the Midwest agricultural stream. Purposeful sampling techniques were used to identify participants whom met the study criteria.

\section{Data Collection}

A qualitative approach was used to examine the potential barriers migrant women farmworkers' experience managing perinatal care. Data were collected using a semi-structured interview guide with 15 migrant women farmworkers during the months of September and October 2014. The interview guide consisted of seven demographic questions followed by 22 opened-ended questions. The open-ended questions covered two main areas: 1) potential challenges to maintaining perinatal care and 2) a typical day and the type of work they participated in during gestation.

The first author conducted all the interviews, the majority of which were conducted in Spanish $(n=13)$. The remaining interviews were conducted in English. All interviews followed the interview guide and were digitally recorded for accuracy and later transcribed. Field notes were also taken during interviews to capture participant's non-verbal reactions and the interviewer's overall perceptions.

\section{Data Analysis}

Each audio recording was transcribed verbatim. NVivo10 was used to manage the qualitative data. Each transcription was read a minimum of three times for coding and identification of common themes. The participant's responses to each interview question were identified, then in a broader sense in relation to the research questions. Next, each transcript was hand coded using an inductive coding approach [21].

\section{Ethical Considerations}

This project was approved by Walden University Institutional Review Board (IRB) for human subjects' research. All data was de-identified and pseudonyms were used to protect the privacy of the study participants. In order for the study to be credible and to make a contribution to the existing literature in the field of perinatal health among migrant women farmworkers it was dependent on the quality of the data collected, data analysis, and verification of findings. Therefore, in order to ensure the study was credible, confirmable, and dependable certain procedures were strictly adhered to throughout data collection and data analysis. The credibility of this study was verified through data triangulation of the sources for data collection. This process involved using different participants from multiple farms in Northern Ohio and several quotes from the participants to support findings. To ensure confirmability in this study the first author used rich descriptions from the study participants and reflexivity. Notes were taken during the interview on the interview guide and during data analysis, highlighting themes as they emerged. Direct quotes provided a rich detailed description of the data from the participant's perspective. Reflexivity also required a conscious self-reflection when the results were analyzed.

The procedure to ensure dependability was confirmed through the use of an audio recording device. The use of an audio recorder produced a more reliable account of the data collected and created a permanent recording of the interviews. Audio recording also eliminated the dependence of recall basis after the interview. Permission to audio record each interview was granted from each participant when they signed the informed consent form prior to beginning the interview. 
Table 1. Demographic Characteristic of Participants

\begin{tabular}{|c|c|c|c|c|c|c|c|}
\hline \#/PSEUD & AGE & NAL & EDU. LEVEL & MS & $\# \mathrm{CHN}$ & \#CHN LOST & \# YRS IN FIELDS \\
\hline 1 Elisa & 26 & Mexico & 10 & $\mathrm{M}$ & 2 & 0 & 10 \\
\hline 2 Maria & 22 & Mexico & 12 & S & 2 & 0 & 5 \\
\hline 3 Lilia & 29 & Mexico & 5 & $\mathrm{M}$ & 2 & 0 & 14 \\
\hline 4 Alejandra & 39 & Mexico & 0 & $\mathrm{~S}$ & 2 & 0 & 16 \\
\hline 5 Rosa & 23 & US & 12 & $\mathrm{M}$ & 3 & 0 & 1 \\
\hline 6 Yolanda & 37 & Mexico & 12 & $\mathrm{M}$ & 5 & 1 & 20 \\
\hline 7 Patricia & 35 & Mexico & 12 & $\mathrm{M}$ & 1 & 0 & 12 \\
\hline 8 Juana & 23 & Mexico & 10 & $\mathrm{M}$ & 3 & 0 & 6 \\
\hline 9 Silvia & 24 & Mexico & 12 & S & 3 & 0 & 9 \\
\hline 10 Martha & 40 & Mexico & 11 & $\mathrm{M}$ & 4 & 1 & 19 \\
\hline 11 Adriana & 25 & Mexico & 12 & $\mathrm{M}$ & 4 & 0 & 5 \\
\hline 12 Leticia & 32 & Mexico & 12 & $\mathrm{D}$ & 2 & 0 & 5 \\
\hline 13 Veronica & 27 & Mexico & 12 & S & 3 & 0 & 4 \\
\hline 14 Margarita & 40 & Mexico & 9 & M & 2 & 0 & 20 \\
\hline 15 Gabriela & 36 & Mexico & 9 & $\mathrm{M}$ & 2 & 1 & 20 \\
\hline \multicolumn{8}{|c|}{$\begin{array}{l}\text { Key: } \\
\text { PSEUD = Pseudonym } \\
\text { NAL= Nationality } \\
\text { EDU=Highest educational level } \\
\text { MS=Marital status } \\
\text { \# CHN }=\text { Number of children } \\
\text { \# CHN LOST = Number of children who have died } \\
\text { \# YRS in field= Number of years working in the fields }\end{array}$} \\
\hline
\end{tabular}

\section{Results}

\section{Participants}

Fifteen women of Hispanic descent form the sample for this study; 14 of who were born in Mexico and one in the US (see Table 1). Participant's ages ranged from 22 to 40 years of age with a mean age of 30.5. The majority of the migrant farmworkers reported their marital status as married $(n=10$; see Table 1). Participant's level of education ranged from no formal education $(n=1)$ to completion of high school $(n=8$; see Table 1). The number of years worked in the fields ranged from one to twenty years (see Table 1). Number of children ranged from one to five children and $20 \%(n=3)$ reported they lost a child during pregnancy (see Table 1).

At the commencement of each interview the migrant women farmworkers were asked their definition of prenatal care to glean an understanding of their health literacy of prenatal practices recommended by the Centers for Disease Control and Prevention [22]. They mentioned a variety of general concepts consistent with prenatal care such as taking prenatal vitamins, eating healthy food, regular checkups, and getting rest.

“Good, you go to doctors' appointments, to have, because at times they give vitamins for the pregnancy, you take folic acids, be aware of the pregnancy, pregnancy you have to take these vitamins, acid, all so that the baby is healthy" (Adriana, 25).
One aspect of prenatal care that varied greatly among participates was when they started prenatal care. When discussing prenatal care all participants were asked when they began prenatal care treatment. It was difficult for many of the women to remember exactly when they started prenatal care and how often they were able to attend appointments but they all provided answers to when they thought they began receiving prenatal care. Answers varied among the women with some beginning prenatal care at one month of gestation and others beginning at four or five months of gestation. The majority of women $(n=10)$ stated they started prenatal care some time during the beginning of the second trimester when they were about four months pregnant. Only two participants stated they began their prenatal care between one to two months of gestation.

\section{Barriers}

When the respondents were asked if they participated in what they understood to be normal prenatal care while working in the fields all 15 stated they could not maintain what they perceived as normal prenatal care due to a variety of barriers. The responses were divided into two broad categories: occupational and access barriers.

\section{Occupational}

The occupational barriers mentioned that inhibited migrant women farmworkers from maintaining prenatal care included long work days, lack of time, and lost wages. 
All 15 women identified the extremely long workdays and the lack of a fixed schedule as barriers to maintaining prenatal care. The women worked from 07:00AM to 07:00PM or 07:30PM Monday -Friday and a half day on Saturdays. During the day they were permitted to take two fifteen-minute breaks and one thirty-minute lunch break.

"It's hard here for a pregnant woman to work outside because, for me one year I worked when I was pregnant of my fourth son, and so it's hard because they don't let you, you can't be missing like some days like to go to appointments. You can't be going in and out, you can't be like snacking, eating is a certain time, so once, like, if you don't eat breakfast in the morning when you go, you start at seven and then you just eat lunch. It's just half an hour for break for lunch and then it's till you come back. So it's very hard to get prenatal care if you're pregnant" (Yolanda, 37).

Additionally, they were not treated differently when in gestation. Ninety-three percent $(n=14)$ of the women stated the work does not change for women who were in gestation. The women stated regardless of pregnancy status women were treated exactly the same and do the same work. They did not take additionally breaks during the day, and they worked the same amount of hours.

"When you are a worker, even if you are pregnant, you are just another worker, that is they don't treat you any differently" (Maria, 22).

"Yes this is very difficult because we work in the fields, and with the strawberries we have to squat all day and with a big stomach it hurts. And then we have carry boxes of strawberries and yes it is difficult" (Elisa, 26).

Lack of time was another occupational barrier that was identified. All 15 of the women discussed how it was difficult to find time to take proper care of themselves during gestation due to their schedules. Their evenings and one day off per week were fully occupied with household chores and caring for their family, leaving little to no free time for self-care and rest.

"We come home and we change and we bath and after we cook and this. We work from 7AM to 7 or 8PM. Some times there isn't enough time to bath because of the hour and you have to cook. And when you have children you do what you can for dinner for them. Bath the kids give them food everything" (Alejandra, 39).

Not getting paid was also mentioned several times $(n=5)$ as an occupational barrier to maintaining prenatal care. The migrant women stated in order to attended prenatal care appointments they would have to take a day off and thus lose a days' wages. Migrant women farmworkers are paid by piecemeal rate. Meaning, if they miss a day of work they do not get paid; they are paid per unit of work performed.
"Yeah, you don't get paid. So there's no like, sick days that they'll pay you or like, you miss it and they'll, you know we don't have any type of benefits that so" (Yolanda, 37).

In addition to the occupational barriers, the study participants identified several barriers to accessing prenatal care while working in the fields in Northern Ohio. The majority of participants $(n=13)$ stated the care they received from medical providers during their tenure in Ohio was good. However, when asked if they experienced any barriers to receiving medical care, two-thirds responded with yes. The three leading barriers to accessing care that inhibited migrant women farmworkers from receiving prenatal care included language, transportation, and fee for service.

The main obstacle migrant women farmworkers faced while accessing prenatal care in Northern Ohio was the language barrier. All the women were of Hispanic descent and $87 \%$ lacked proficient English language skills. Spanish was the primary language for the women; however, all of the medical providers in the area speak English. Therefore, in order to receive prenatal care from providers in Ohio the migrant women were responsible for arranging and paying for a Spanish language interpreter in order to communicate with the doctor during their appointments.

"Yes, it was a struggle to have my babies here... because here there are no clinics and you have to look for someone to interpret and pay them to come with me because I didn't understand the doctor" (Maria, 22).

A lack of transportation to the clinic was also mentioned as a barrier to receiving care. Many of the migrant women did not drive or did not have access to a car $(n=13)$. Therefore, they had to rely on their spouse, a neighbor, or another family member to drive them to appointments. The prenatal care providers were approximately thirty to forty minutes away from the migrant camp therefore the women had to take an entire day off of work to attend appointments. Sometimes, their spouse or partner had to take the day off too to provide transportation.

"Here it is a problem, the doctors do not speak Spanish. The one problem is the clinic is far away, my husband takes me, it takes about 40 minutes to get there. I do not remember what town it is in but it is far away. If I need to go I have to ask permission to miss an entire day" (Lilia, 29).

The third access barrier identified was a lack of health insurance and difficulty having to pay for services. The state of Ohio does not provide Medicaid or financial assistance for migrant farmworkers during their tenure in the state. Therefore, if they do not have insurance coverage they pay out of pocket for services.

"In Florida I have Medicaid but here no. I do not have insurance so I have to pay" (Juana, 23). 
One of the Farms participating in the study had a federally funded migrant clinic on-site; however, the clinic did not offer prenatal care and it was only open one day a week from 8:00 AM to 4:00 PM.

"There is a clinic here but it is not for woman who are pregnant. It is for when you have a cold" (Alejandra, 39).

When participants were discussing barriers to receiving medical care in Ohio, $47 \%(n=7)$ stated they had at least one cesarean birth. One migrant woman stated she worked till the end of her pregnancy and that is why she had a cesarean delivery.

"I still worked because my daughter does not have a papa and I was single so I worked. For this I struggled a lot because she didn't have a papa so I worked. When she was born I worked until they cut my belly, I had a cesarean section" (Alejandra, 39).

Another woman stated she had a cesarean delivery because the baby was breech. She didn't know if the baby was breech because of working in the fields or not, but she thought her work might have something to do with the complicated birth.

"I took work when I was pregnancy because almost never, very seldom said I cannot work. When I had aches and nausea I almost never gave up. Then, I don't know if it was the work or not but she \{baby\} grew sitting \{breech\} so I had to have a cesarean. I don't know if it was because of the work or not but she was sitting $\{$ breech\} so they had to do a cesarean" (Martha, 40).

Additionally, one woman stated she had to have a cesarean delivery because she worked until the day before giving birth and she didn't have the strength to push. Yolanda stated she had multiple cesarean deliveries and has been working in the fields for twenty years. She stated she worked to the day of delivery for every pregnancy because she needed the money.

"I worked the entire pregnancy, mostly, and it was hard. And so all the strength, you would leave all the strength on the fields, there's no strength to push, there's no strength to breath it out, nothing, it's like the only option I had was a cesarean, I was so weak, I couldn't, I couldn't do nothing really, like that was like the last option. So it does affect because of our work is not the same as a pregnant lady not working, taking care of like being at home, you know, getting their rest, getting their sleep, getting their healthy foods and snacks and all that. All that we can get outside is just work, work, work, we can't really" (Yolanda, 37).

Family Planning

As a result of the numerous barriers to receiving prenatal care in Northern Ohio two thirds $(n=10)$ of the women stated they tried to loosely plan their pregnancies around their migration to Northern Ohio to avoid having to use the health care system for delivery. Two thirds of the women stated they planned their deliveries so they could give birth in Florida $(n=4)$ or Texas $(n=6)$ for two reasons: a) they can find medical providers that speak Spanish and b) both states offer free community-based health care for community members regardless of their ability to pay or residency status [19]. In both of these states the migrant women stated they were eligible for health care upon their return after the harvest in Ohio. Not having to worry about health care costs for delivery reduced the financial burden for the women and their families.

\section{Postnatal Care}

In addition to prenatal care, part of perinatal care management is postnatal care. Therefore, each of the women were asked if they attended postnatal care appointments and how often. Although all 15 women were asked about attending postnatal appointments, only four participants answered the question. Two participants stated they attended one postnatal appointment at a hospital, one stated she had postnatal care from friends, and the fourth participant stated she didn't attend any appointments.

"After pregnancy I went eight days after birth and then I did not go back" (Gabriela, 36).

\section{Discussion}

Based on the analysis of the in-depth interviews, migrant women farmworkers faced several barriers that inhibited the management of perinatal care to ensure healthy pregnancy outcomes for both mother and child. All of the participants discussed intrapersonal constructs regarding prenatal care and during the interview the varying levels of health literacy regarding perinatal care was evident. The responses ranged from "take care, no more" to one respondent discussing her appointments with her gynecologist, and another discussing the importance of eating well and getting plenty of rest. Nevertheless, the majority of migrant women farmworkers were not able to maintain what they identified as normal perinatal care while working in the fields in Northern Ohio.

According to the Centers for Disease Control and Prevention early enrollment in prenatal care and proper weight gain can reduce the risks of poor birth outcomes [13]. Beginning prenatal care prior to gestation or soon thereafter is viewed as a necessity and a preventive public health intervention to reduce maternal mortality and morbidity and poor birth outcomes $[22,23]$. Despite the importance of prenatal care early on, only $13 \%$ of the women in this study began prenatal care during the first trimester, $66 \%$ began at the beginning of the second trimester, and the other $20 \%$ during the middle to end of the second trimester. Similarly, Quelopana et al. [24] found that only 35\% of Hispanic women began prenatal care during the first trimester; and in California only $42 \%$ of migrant women farmworkers began prenatal care during the first trimester [1]. 
There were several occupational barriers that impeded the women from receiving prenatal care. The first barrier was their long workdays. All of the women reported having to work 12-13-hour per day five days a week and half a day on Saturdays. During the busy season they are tasked with working Sundays as well. This is consistent with the nature of migrant farmwork in the United States [6]. Based on reports from the participants, whether in gestation or not, the work did not change. The work was strenuous, as they had to be on their knees or bending down all day. Farmwork is rated as one of the most dangerous occupations in the US [25] and is known to be extremely labor intensive [6]. One woman discussed how at the beginning of the season it is common for her knees to be very sore until they "become molded." Several other women discussed the difficulty working through pregnancy because of fatigue and the additional weight of the belly. According to Banerjee [26] standing for long periods and heavy lifting increased the risk of pre-term births and miscarriages.

The migrant women worked in all weather conditions including sun, rain, and hot and cold climates with no shade or protection from the elements. Kelley et al. [27] identified heat related illnesses as causing adverse pregnancy outcomes for migrant women. According to participants, one of the farms provided rain suits for the migrant workers, while workers at the other farms had to purchase their own protective clothing if they desired to wear it. All the farms provided access to water and bathrooms on site within close proximity to the workers. However, for the women in gestation it was difficult to walk to the bathroom all the time during the second and third trimesters.

Working 12-13-hours per day during the weekdays left no time for the women to attend prenatal care appointments and the only time clinics were open was 8:00 AM to 4:30 PM, Monday -Friday. Therefore, if the women decided to attend prenatal care appointments they had to take a day off from work, resulting in lost wages.

Losing an entire days' worth of wages was a concern for just over a third of the respondents. In order to attend prenatal care appointments the women had to miss the entire day; thus, making them decide between attending prenatal care appointments or working to earn money. The women earn approximately $\$ 100.00$ per week therefore losing a days' wages was a substantial factor in deciding whether to get care.

The last occupational barrier that inhibited the women from receiving prenatal care was a lack of time. All of the women discussed having no time to care for oneself as a barrier. The women described working from dawn to dusk in the fields then returning home to manage their household such as cooking, cleaning, and caring for their children. In addition to no time to attend clinical appointments, the women were left with no time for self-care such as eating properly, getting exercise, and resting, all of which are recommended to ensure a healthy pregnancy for both the mother and child [13].
In addition to the occupational barriers inhibiting migrant women from participating in prenatal care, they also discussed several barriers to accessing perinatal care while in Northern Ohio. When the women were asked their overall opinion of the medical care during gestation, $87 \%$ stated the care they received while in Northern Ohio was good. The other $13 \%$ stated they have never used maternal care services in Northern Ohio. The 13\% not using prenatal care were pregnant during part of the fieldwork season but did not see a provider while in Ohio; they stated they wait until they return to Texas or Florida to begin prenatal care.

When asked about accessing perinatal care services two-thirds of the respondents stated at least one barrier. The most common barrier stated by the women was a lack of Spanish speaking providers or interpreters in the area. The majority of the women have little to no English language skills and they stated the providers in the area did not speak Spanish. According to the NCFH language and cultural factors are barriers to migrant farmworkers ability to access health care in the United States [1].

Additionally, the providers in the local area did not have interpreters available. Therefore, in order to receive perinatal care the women had to arrange for and pay for an interpreter to accompany them to their appointments. Having to pay for an interpreter was a financial burden for the women, who were already losing a days' wages to attend their appointment. Previous research has linked language barriers including a lack of interpreters to poor health outcomes for Hispanic immigrant populations [28-30].

Another barrier to accessing perinatal care services was a lack of transportation to get to appointments. The majority of clinics offering maternal care services were about 40-50 minutes away by car. Due to the rural location of the migrant camps, public transportation was not an option; therefore, the women had to find someone to take them to their appointment. A lack of transportation has been documented to be a barrier in receiving medical care in rural settings for Latino children $[28,30]$. Having to rely on someone else to take them to their appointments also resulted in lost wages for the person taking them. Typically, it was a spouse or another family member accompanying them, thus two workers in the same household would lose wages for the day.

The next barrier the women experienced was paying out-of-pocket for perinatal care services. In the United States, roughly $5 \%$ of migrant farmworkers have medical insurance $[28,31]$. Thus, drawing from a public policy influence on health behaviors the federal government initiated a migrant health care program. The federal government subsides approximately 400 migrant health clinics and mobile units across the United States that provide free health care to migrant farmworkers, but the clinics and mobile units are not all encompassing [9]. For example, one farm had a migrant clinic on-site but the clinic, which was open one day a week from 8:00 AM -4:00 PM, did not offer perinatal care. This is a common practice with clinics and community health centers throughout the United States due to the high cost of malpractice insurance for obstetrical services [31]. 
The migrant women farmworkers had to pay for prenatal care services but were exempt from paying for labor and delivery services. According to the Personal Responsibility and Work Opportunity Act of 1996 undocumented workers are eligible for emergency medical services including the cost of labor and delivery services [17]. This is a federal program for undocumented immigrants who meet eligibility requirements such as low-income to cover emergency medical costs using public funds [17]. Therefore, several of the women had deliveries while in Northern Ohio and didn't have to pay for delivery costs under this Act.

Another means the women found to circumvent paying for prenatal care services and labor/delivery charges were to receive prenatal appointments and give birth after the field season when they returned to Florida or Texas. Both States offer health care to migrant farmworkers regardless of immigration status or residency. Sixty-seven percent of the women planned their pregnancy around their migration to Ohio. Additionally, the women could easily find providers in Florida and Texas that speak Spanish therefore they did not have to pay for an interpreter. Because of this, several women stated they wished they could find work in Florida or Texas instead of having to travel "all the way up here."

Another theme that was discovered during data analysis was the higher than average number of cesarean deliveries. Forty-seven percent of the women stated they had at least one cesarean delivery with several women stating they had multiple cesarean deliveries. The national average for cesarean delivery is one in four women [32]. The women offered a variety of reasons why they believed they had to have a cesarean delivery including no energy to push, preeclampsia, breech baby, and low amniotic fluid. Yolanda, who has been working in the fields for 20 years, stated she had several cesarean deliveries because she had no energy to push when it came time to give birth. She stated she had to no energy to push because she worked from dawn to dusk 5 days a week and half a day on Saturdays, cared for her children, did household chores, cooked, shopped, and did laundry, leaving no time to eat properly, get enough sleep, and take care of herself.

After giving birth, it is recommended by providers to participate in postnatal care for 4-6 weeks after delivery [18]. Only three participants attended postnatal care appointments. Two of the women attended formalized postnatal care appointments with a medical provider and the other participant stated she received postnatal care from her friends and family.

Part of postnatal care is resting and allowing time for recovery after giving birth. All of the women had time off after giving birth although they did not call it maternity leave. The ten women who gave birth in Florida or Texas after the fieldwork season ended in November were without work until they returned to Ohio in May the following year. Therefore, depending on the date of birth they had several months without work. The most common amount of time not working after giving birth was between two and three months. This is similar to the average amount of maternity leave taken in the United States, which is between 10-12 weeks [22]. However, one participant, Yolanda who has five children, the majority by cesarean, returned to work 7-10 days after giving birth each time because she needed the money.

There were several limitations to this study including but not limited to a small sample size, sampling design, specific geographical location and potential for bias. The first limitation was the small sample size of 15 participants. The limited sample size may not truly represent the perceptions and beliefs of migrant women farmworkers within the larger population. Secondly, the study was limited to a non-random sampling design, which restricts the ability to generalize the study findings. Thirdly, all study participants resided in migrant camps in Northern Ohio therefore the results may not be representative of the geographical makeup of migrant women farmworkers outside of the study area. Additionally, the responses to interview questions were self-reported by the study participants; thus, there is a possibility of recall bias or misrepresentation of facts. Lastly, the study findings were limited to farms that allowed the first author access to the migrant camps to conduct interviews on their property.

\section{Conclusions}

The findings of this study have implications for social change by acknowledging the barriers that inhibit migrant women farmworkers from managing perinatal care. Participating in perinatal care, pre-and post, is recommended to reduce adverse pregnancy outcomes. However, the study participants were not able to maintain perinatal care; thus, jeopardizing their health and the health of their unborn child.

Current regulations in many states, including Ohio, do not guarantee access to maternal healthcare for migrant women. Therefore, findings from this study can be used to influence local, state and national health care organizations towards developing a more comprehensive maternal health care program for migrant women farmworkers. Further research is needed to explore perinatal care with a larger geographical area and explore pregnancy outcomes for this underserved population.

\section{REFERENCES}

[1] National Center for Farmworker Health. (NCFH). Farmworker health factsheet. Demographics. 2012. Retrieved from

http://www.ncfh.org/docs/fsMigrant\%20Demographics.pdf.

[2] U.S. Department of Agriculture. Economic Research Service. Farm sector income and finances: 2014 Farm sector income forecast. 2014. Retrieved from http://www.ers.usda.gov/topics/farm-economy/farm-sector-i ncome-finances/2014-farm-sector-income-forecast.aspx.

[3] Anthony M, Williams JM, Avery AM. Health needs of 
migrant and seasonal farmworkers. Journal of Community Health Nursing. 2008;25(3):153-160.

[4] National Center for Farmworker Health. (NCFH). Farmworker health factsheet. Facts about farmworkers. 2009. Retrieved from http://www.ncfh.org/docs/fsFacts\%20about\%20Farmworker s.pdf

[5] Villarejo D. The Health of U.S. Hired Farm Workers. Annual Review of Public Health. 2003;24:175-193.

[6] Anthony M, Williams JM, Avery AM. Health needs of migrant and seasonal farmworkers. Journal of Community Health Nursing. 2008;25(3):153-160.

[7] Bethel JW, Walsh J, Schenker MB. Preterm, low-birth-weight deliveries, and farmwork among Latinas in California. Journal of Occupational and Environmental Medicine / American College of Occupational and Environmental Medicine. 2011;53(12):1466-1471.

[8] Habib RR, Fathallah FA. Migrant women farm workers in the occupational health literature. Work. 2012;41: 4356-4362.

[9] Hansen E, Donohoe M. Health Issues of Migrant and Seasonal Farmworkers. Journal of Health Care for the Poor and Underserved. 2003;14(2):153-164.

[10] Landale NS, Oropesa RS, Bradatan C. Hispanic families in the United States: Family structure and process in an era of family change. In: National Research Council (US) Panel on Hispanics in the United States; Tienda M, Mitchell F, editors. Hispanics and the Future of America. Washington (DC): National Academies Press (US). 2006.

[11] Kelly Y, Panico L, Bartley M, Marmot M, Nazroo J, Sacker A. Why does birthweight vary across ethnic groups in the UK? Findings from the Millennium Cohort Study. Journal of Public Health. 2008;31(1):131-137.

[12] Smith LK, Manktelow BN, Draper ES, Springett A, Field DJ. Nature of socioeconomic inequalities in neonatal mortality: population based study. British Medical Journal (Clinical Research Ed.). 2010;341:c6654.

[13] Tomé T, Guimarães H, Bettencourt A, Peixoto JC. Neonatal morbidity-mortality in very low birth weight in Europe: the Portuguese experience. The Journal of Maternal-Fetal \& Neonatal Medicine: The Official Journal of the European Association of Perinatal Medicine, the Federation of Asia and Oceania Perinatal Societies, the International Society of Perinatal Obstetricians. 2009;22(S3):85-87.

[14] Balaam MC, Akerjordet K, Lyberg A, Kaiser B, Schoening E, Fredriksen AM, ... Severinsson E. A qualitative review of migrant women's perceptions of their needs and experiences related to pregnancy and childbirth. Journal of Advanced Nursing. 2013;69(9):1919-1930.

[15] Bircher HM. Prenatal care disparities and the migrant farm worker community. Journal of Maternal Child Nursing. 2009;34(5):303-307.

[16] Daniels P, Noe GF, Mayberry R. Barriers to prenatal care among black women of low socioeconomic status. American Journal of Health Behavior. 2006;30(2):188-198.

[17] Reed MM, Westfall JM, Bublitz C, Battaglia C, Fickenscher A. Birth outcomes in Colorado's undocumented immigrant population. British Medical Journal Public Health. 2005;5(1): 100 .
[18] Rodríguez C, Rivières-Pigeon C. A literature review on integrated perinatal care. International Journal of Integrated Care. 2007;19:1-15.

[19] Wallace SP, Torres J, Sadegh-Nobari T, Pourat N, Brown ER. Undocumented immigrants and health care reform. In: UCLA Center for Health Policy Research. 2012. Retrieved from http://healthpolicy.ucla.edu/publications/Documents/PDF/un documentedreport-aug2013.pdf

[20] Magana CG, Hovey JD. Psychosocial Stressors Associated with Mexican Migrant Farmworkers in the Midwest United States. Journal of Immigrant Health. 2003;5(2):75-86.

[21] Thomas DR. A general inductive approach for analyzing qualitative evaluation data. American Journal of Evaluation. 2006;27(2):237-246.

[22] Centers for Disease Control and Prevention. Reproductive health: Maternal and infant health. 2013. Retrieved from http://www.cdc.gov/reproductivehealth/MaternalInfantHealt $\mathrm{h} /$ index.htm.

[23] Alexander GR, Kotelchuck M. Assessing the role and effectiveness of prenatal care; History, challenges, and directions for future research. Public Health Reports. 2001;116(4).

[24] Quelopana A, Champion JD, Salazar BC. Psychosocial factors predicting prenatal care in Mexican Women. Midwifery. 2009;25(3):277-85.

[25] U.S. Department of Labor. Field operations handbook. Chapter 36: Field sanitation and temporary labor camp standards in agriculture under the Occupational Safety \& Health Act. 2014b. Retrieved from http://www.dol.gov/whd/FOH/FOH_Ch36.pdf.

[26] Banerjee B. (2009). Physical hazards in employment and pregnancy outcome. Indian Journal of Community Medicine. 2009;34(2):89-93.

[27] Kelley M, Flocks JD, Economos J, McCauley LA. Female farmworkers' health during pregnancy. Workplace Health \& Safety. 2013;61(7):308-313.

[28] Cristancho S, Garces DM, Peters KE, Mueller BC. Listening to rural Hispanic immigrants in the Midwest: a community-based participatory assessment of major barriers to health care access and use. Qualitative Health Research. 2008;18(5):633-646.

[29] Perez-Escamilla R, Garcia J, Song D. Health care access among Hispanic immigrants: ¿Alguien esta escuchando? [Is anybody listening?]. Special Issue: Anthropological Perspectives on Migration and Health. 2010;34(1):47-67.

[30] Flores G, Abreu M, Olivar MA, Kastner B. Access barriers to health care for Latino children. Archives of Pediatric Adolescent Medicine. 1998; 152(11):1119-1125.

[31] Warrick LH, Wood AH, Meister JS, De Zapien JG. Evaluation of a peer health worker prenatal outreach and education program for Hispanic farmworker families. Journal of Community Health. 1992;17(1).

[32] Osterman MJK, Martin JA. Changes in cesarean delivery rates by gestational age: United States, 1996-2011. NCHS data brief, no 124. Hyattsville, MD: National Center for Health Statistics. 2013. 